\title{
O agronegócio do milho e a modernização agrícola na sub-bacia do rio salgado
}

The agribusiness corn and modernization in agricultural river sub-basin salgado

\author{
ARAÚJO ${ }^{1}$, H. M.; OLIVEIRA ${ }^{2}$, A. M.; CRUZ ${ }^{3}$, R.; $\mathrm{SOUZA}^{4}$, A. C.
}

heliomarioaraujo@yahoo.com.br

\begin{abstract}
Resumo
Esta investigação cientifica delimita como área de estudo a Sub-bacia do rio Salgado, localizada na porção centrooeste do estado de Sergipe e tem como objetivo geral analisar os impactos ambientais ocasionados pelo avanço do agronegócio do milho em seu território no período 2003/2013. A pesquisa fundamenta-se na concepção sistêmica de análise da paisagem e na apropriação do espaço como categoria específica da geografia. Para a concretização dos objetivos propostos utilizaram-se diversos procedimentos metodológicos associados a diferentes etapas, destacando-se o levantamento bibliográfico e de documentos, a produção cartográfica, a realização de entrevistas e o trabalho de campo. Entre outros resultados, verificou-se que os indicadores de modernização agrícola considerados na pesquisa mostram a tendência de expansão das áreas de cultivos na subbacia. Além disso, a presença da biotecnologia e das modernas máquinas agrícolas reflete a imagem do setor agropecuário como altamente inovador no âmbito econômico, mas permanecendo resistente no aspecto socioambiental.
\end{abstract}

Palavras-chave: Agronegócio; Milho; Impactos ambientais.

\begin{abstract}
This scientific research defines as the study area the Subbasin of the Salt River, located in the central-western portion of the Sergipe state and has as main objective to analyze the environmental impacts caused by the advance of corn agribusiness in its territory in the period $2003 / 2013$. The research is based on the systemic concept of landscape analysis and appropriation of space as a specific category of geography. To achieve the proposed objectives we used different methodological procedures associated with different stages, highlighting the literature and documents, cartographic production, conducting interviews and fieldwork. Among other results, it was found that the agricultural modernization indicators considered in the survey show the trend of expansion of areas of crops in the sub-basin. Moreover, the presence of biotechnology and modern agricultural machines reflects the image of the agricultural sector as highly innovative in the economic, but remaining strong in the environmental aspect.
\end{abstract}

Keywords: Agribusiness; Corn; Impacts Environmental.

\section{INTRODUÇÃO}

O aumento expressivo da área cultivada, a elevada produtividade e a inserção de diversos equipamentos agrícolas no processo produtivo têm consolidado a modernização agrícola e o fortalecimento do agronegócio no território brasileiro.

Essa modernização, como parte integrante do processo capitalista de desenvolvimento a que está submetido o campo, exprime-se de maneira contraditória, sendo o crescimento da produção e da produtividade assimilados de forma positiva e negativa pelos resultados perversos do ponto de vista de suas implicações socioambientais.

Assim, o capital e sua materialização com o agronegócio de grãos no Brasil estão promovendo mudanças na utilização da terra, nas relações de trabalho e na implantação de novas tecnologias no campo. A expansão da área colhida, da produção e melhorias no rendimento médio 
do cultivo demonstram a reestruturação no processo produtivo e o consequente caráter modernizador da agricultura. Neste sentido, as alterações ambientais decorrentes da introdução dessas novas tecnologias no campo têm colocado em discussão seus aspectos negativos, sobretudo no que se refere à qualidade do meio ambiente e aos desequilíbrios causados pelas monoculturas aos ecossistemas.

A expansão do agronegócio por sua vez vem acompanhada da intensa exploração dos recursos naturais e de uma maior subordinação do campo à agroindústria, processo característico da modernização agrícola. Busca-se incessantemente maior produtividade e as preocupações com as questões socioambientais não acompanham paralelamente esse caráter modernizador da produção agropecuária.

Portanto, a ampliação da produção agrícola de milho e a carência de uma abordagem teórica relacionada ao uso e manejo do solo na sub-bacia do rio Salgado, justificou a realização desta pesquisa voltada para a compreensão dessa dinâmica desencadeada com a intervenção antrópica no agronegócio do milho e suas possíveis consequências danosas para a biodiversidade da área (Figura $01)$.

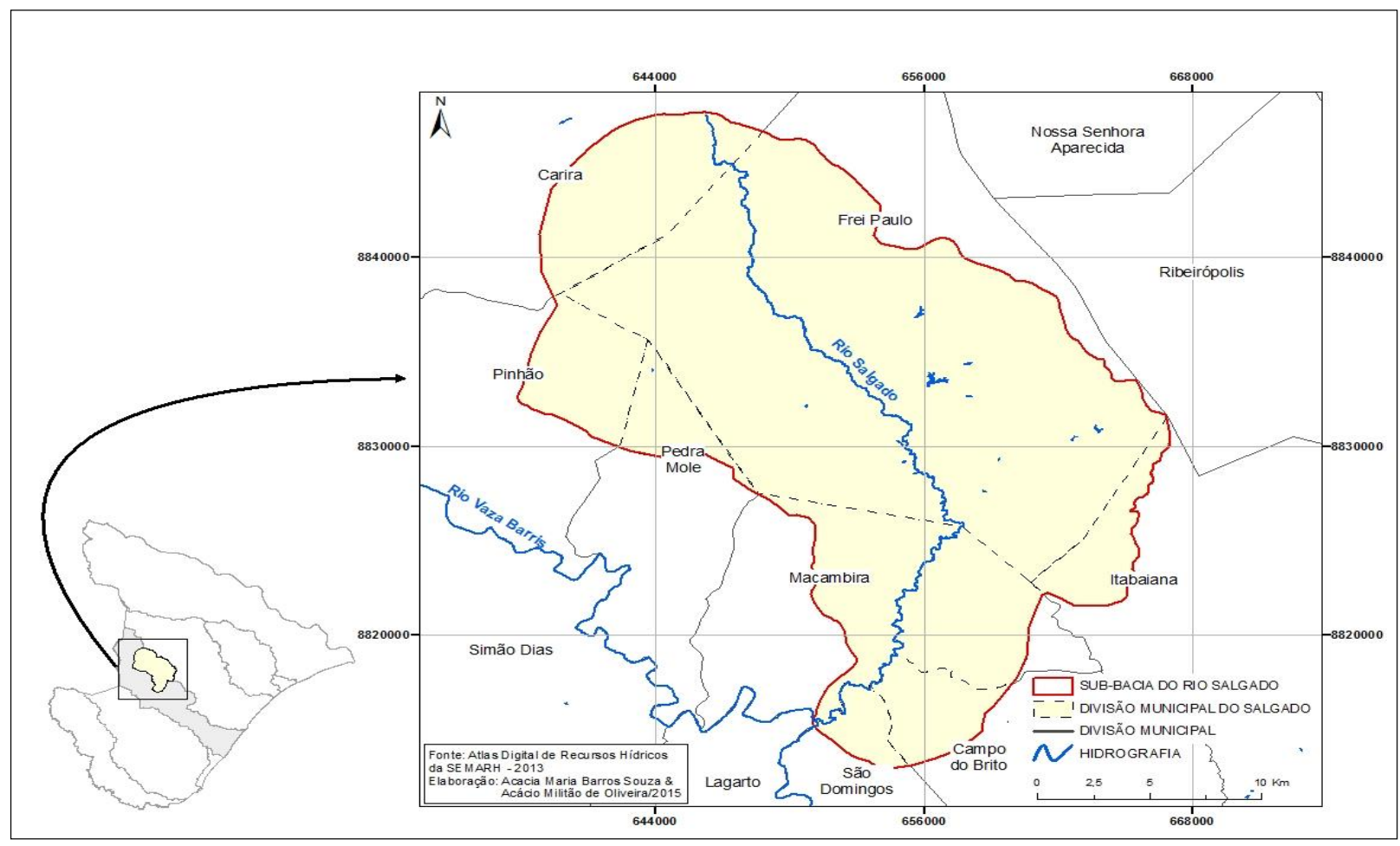

Figura 01: Localização Geografica da Sub-bacia do Rio Salgado 


\section{METODOLOGIA}

A pesquisa se desenvolveu em quatro fases. Inicialmente, em gabinete, realizou-se o levantamento bibliográfico e a documentação cartográfica básica, além do conhecimento dos dados e informações sobre os atributos e propriedades dos componentes físicos e bióticos, através de estudos geológicos, geomorfológicos, pedológicos, climáticos, hidrológicos e fitogeográficos da área da sub-bacia.

Após consolidação da base teórica e da paralela produção textual, a pesquisa delineou-se para a fase de campo, visando reconhecer os elementos físico-naturais componentes da sub-bacia e os condicionantes socioeconômicos atrelados ao agronegócio. Para isso, foram realizadas 14 observações nas principais áreas produtores de milho entre os meses de maio a novembro de 2015. $\mathrm{O}$ quadro 01 apresenta um resumo dos principais pontos visitados e destaca alguns objetivos norteadores da pesquisa de campo.

Além das observações em campo, foram realizadas 3 (três) entrevistas com o Subgerente do Banco do Brasil da Agência de Frei Paulo, 1 (uma) com o gerente da Rural Produtos Agropecuários e mais 1 (uma) com um dos engenheiros agrônomos prestador de assistência em diversos cultivos na área da sub-bacia.

$\mathrm{Na}$ aplicação do questionário observou-se como critério o tamanho da área cultivada, a condição de ser ou não proprietário de terra, e de cultivarem nas proximidades do rio Salgado._O questionário apresentou questões abertas e fechadas, com direcionamento para 4 (quatro) grandes proprietários de terras plantadores de milho, 4 (quatro) arrendatários e 2 (dois) pequenos produtores rurais. Devido à dificuldade de contato e pouca disposição de outros produtores rurais em colaborarem com a pesquisa não foi possível a ampliação de amostras com esse instrumento.

Ainda nesta fase de campo utilizou-se o GPS e a câmera fotográfica digital, que serviram de base para registrar os diversos cenários apresentados na paisagem da sub-bacia, além do uso de caderneta de campo que possibilitou descrever o grau de degradação ambiental evidenciado pela ação antrópica com a introdução da cultura do milho na área.

A terceira e última fase consistiu na produção cartográfica, com a elaboração das representações específicas dos condicionantes físico-ambientais predominantes na área da sub-bacia (clima, geologia, hidrogeologia, geomorfologia e hidrografia). Nesta fase, buscou-se o apoio da Cartografia Digital e do Geoprocessamento, utilizando-se alguns programas computacionais, como o ArcGis, para o mapeamento utilizou-se a base cartográfica do Atlas Digital sobre Recursos Hídricos de Sergipe/SRH, versão 2013. 


\section{RESULTADOS E DISCUSSÃO}

\subsection{O Agronegócio do Milho e a Modernização Agrícola}

Segundo a base de dados do IBGE (2013), no estado de Sergipe tem ocorrido um aumento da área plantada e da produção de milho nos últimos dez anos (Figura 02). Todavia essas mudanças são decorrentes da intensidade de exploração dos cultivos, ao elevado nível de modernização no manejo dos cultivos e aos crescentes investimentos de capitais nas lavouras.

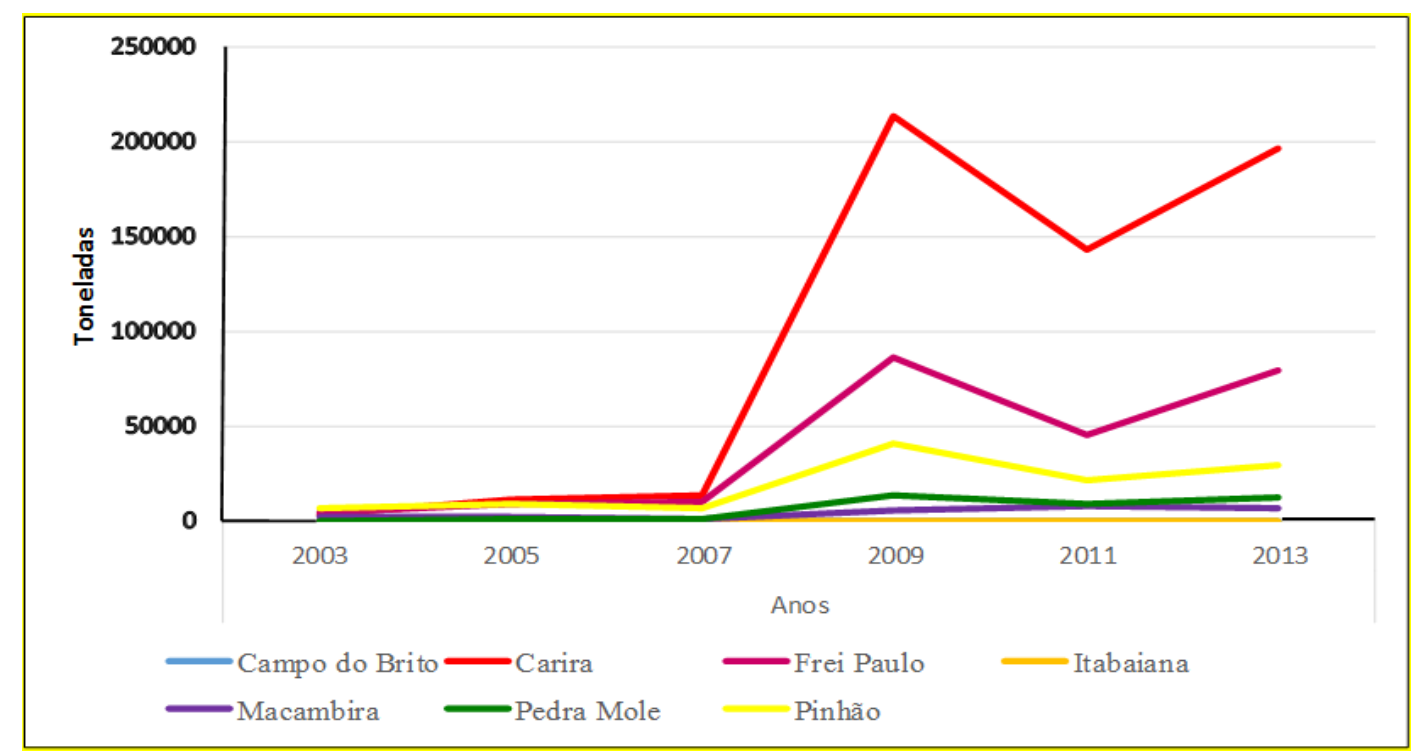

Figura 02: Sub-bacia do rio Salgado - Quantidade de Milho Produzida, 2013.

Fonte: IBGE - Produção Agrícola Municipal, 2013.

As análises dos valores da figura 2 evidenciam a pujança da produção de milho dos municípios de Carira e Frei Paulo, que no período de 2003 a 2013, apresentaram um crescimento de valores aproximados a 5000\% e de 1700\%, respectivamente. Na referida década, destaca-se 2009 como o ano ápice da produção de milho entre os municípios com maior produção. Entretanto, tomando-se como referência o ano de 2009, observa-se que em 2011 ocorreu uma redução de $32,8 \%$ na produção de Carira e de $47,1 \%$ na produção do município de Frei Paulo. Esta queda decorreu da irregularidade climática, fato que provocou prejuízos financeiros, mas não o abandono das lavouras nos anos seguintes.

O capital direcionado ao agronegócio tem-se ampliado e a tendência encaminha para uma maior exploração dessa atividade na área da sub-bacia. Quanto ao capital, este provém da renda dos grandes proprietários rurais (sendo a maioria deles comerciantes local) e do crédito bancário concedido aos arrendatários e outros produtores rurais. Esses elevados investimentos estão 
fortalecendo a maior integração da cadeia produtiva do milho, e também está contribuindo para a especulação do valor da terra, fatos que justificam as diversas mudanças no espaço rural.

Contudo, de acordo com os dados de campo e ao considerar a safra atual de 2015, percebese o elevado número de financiamentos, o aumento nas vendas de máquinas e sementes, além de outros indicadores que demonstram a ampliação dos cultivos de milho na área da sub-bacia. Entretanto, as informações obtidas nos questionários da pesquisa chamam atenção para a provável queda de cerca de $20 \%$ nesta safra, sendo consequência da baixa pluviosidade no final do ciclo de cultivo das plantações.

Apesar da dependência climática, o agronegócio do milho se fortalece e a concretização dos significativos investimentos está se refletindo na ampliação dos cultivos com o grão. Percebe-se diversas paisagens tomadas pelas plantações de milho, retratando inclusive a ocupação de áreas com relevo ondulado e de planícies fluviais, que naturalmente corresponderiam às áreas cobertas de mata ciliar. Assim, até as porções de terras que deveriam ser protegidas por conta da presença de formações vegetais estão sendo utilizadas sem nenhuma observância legal com os cultivos de milho.

\subsection{A Tecnificação da Produção Agrícola}

Na sub-bacia do rio Salgado, o uso da mecanização agrícola (tratores e implementos agrícolas), das sementes transgênicas e a intensa exploração da terra estão modificando de forma abrupta a área agrícola, transformando-a em uma importante produtora de grãos no estado. Assim a tecnologia cumpre um papel determinante no progresso do agronegócio na área, tomando-se como referência a qualidade das sementes plantadas, a diversidade de insumos agrícolas e a quantidade de máquinas e equipamentos agrícolas, devido às demandas das lavouras de milho.

Neste processo de modernização da agricultura, o uso de tratores agrícolas, grades, plantadeiras, colheitadeiras e outros implementos agrícolas representa uma das bases de manutenção do agronegócio. A necessidade de utilização desses implementos justifica o elevado número de equipamentos vendidos no período 2001/2015 (Figura 03). Porém estes dados representam um indicador do quantitativo de vendas de somente 01 (uma) loja comercial durante o período de 4 anos. As informações de outras lojas comerciais de marcas concorrentes tornaram-se inviáveis, pois as mesmas não regionalizam as vendas dos produtos agrícolas, ou seja, os dados abrangem todo o Estado de Sergipe e partes da Bahia.

Além da presença das máquinas agrícolas como exemplos comprobatórios da modernização técnica inserida no cultivo de milho, cabe acrescentar a inserção de diversos implementos e de práticas agrícolas que constituem indicadores do nível de tecnificação da produção das lavouras. 
Como exemplo do uso de novas tecnologias no manejo da cultura, associada ao uso de máquinas e equipamentos agrícolas cita-se a presença de produtos químicos utilizados no controle de pragas e doenças que atingem a monocultura do milho. Nas modernas lavouras de milho o uso da adubação nitrogenada por exemplo, e dos produtos químicos utilizados na prevenção e combates de pragas e doenças representam itens essenciais no cultivo dos grãos.

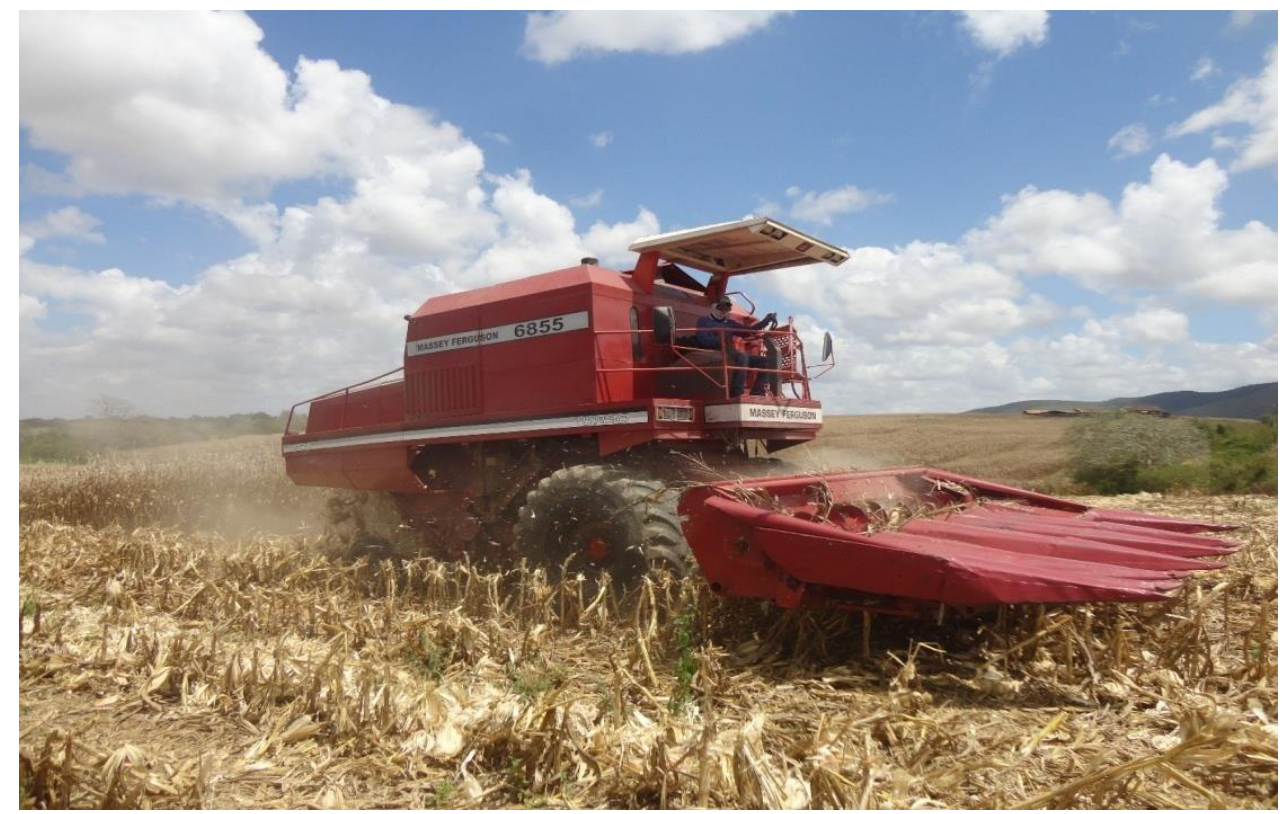

Figura 03: Colheitadeira de Milho na Fazenda Queimadas em Frei Paulo/SE.

Fonte: Autores, 2015.

\subsection{Estrutura Fundiária e Produção Agrícola}

A concentração de terras na sub-bacia, decorre pelo fato das lavouras de milho ocupar propriedades extensas, devido a facilidade no manejo da cultura e na possibilidade de maior produção. As médias e grandes propriedades são as que apresentam expressivo aparato tecnológico e capitais voltadas para o cultivo dos grãos, garantindo-lhes maior produção e produtividade. Já os pequenos proprietários estão à margem do lucro gerado pelo milho, pois não se dispõem de terras, técnicas e de capitais suficientes para cultivar grandes lavouras. À exceção ocorre quando o pequeno proprietário assume a condição de arrendatário. Verifica-se, portanto, que a produção de milho proporciona uma maior acumulação de capitais nas mãos de poucos, atrelada à força e às estratégias de manutenção do agronegócio, trazendo como consequências as desigualdades socioeconômicas e diversos conflitos.

A estrutura atual no conjunto da sub-bacia reforça a tendência cada vez mais concentradora da terra, ainda bastante enraizada no âmbito dos municípios. Assim, considerando que a estrutura fundiária é variável de acordo com o município, a faixa de área estabelecida pelo Instituto Brasileiro 
de Colonização e Reforma Agrária (INCRA) demonstra o quanto as médias propriedades agrícolas dominam a área rural da sub-bacia.

Em termos de ocupação agrícola, na Sub-bacia os cultivos de milho comercial predominam nas médias e grandes propriedades onde apresentam maior nível de modernização, em função do elevado poder financeiro de seus proprietários. Nas pequenas propriedades há o predomínio dos cultivos em regime de policultura marcado pela falta de recursos tecnológicos para mecanizar sua produção através da compra de tratores e defensivos agrícolas.

\subsection{A Intervenção do Estado no Processo de Consolidação do Agronegócio do Milho}

A viabilização do agronegócio do milho na área da sub-bacia provém da junção do capital estatal com o privado, associados aos interesses de empresas de diversos ramos agropecuários (máquinas e equipamentos agrícolas, fertilizantes, agrotóxicos e outros). Destaca-se nessa relação a atuação do Estado como o principal financiador dos cultivos de milho. Para os agricultores beneficiados com os créditos concedidos pelos Bancos Públicos, o financiamento bancário constitui a condição indispensável e a garantia da realização dos cultivos (Figura - 04).

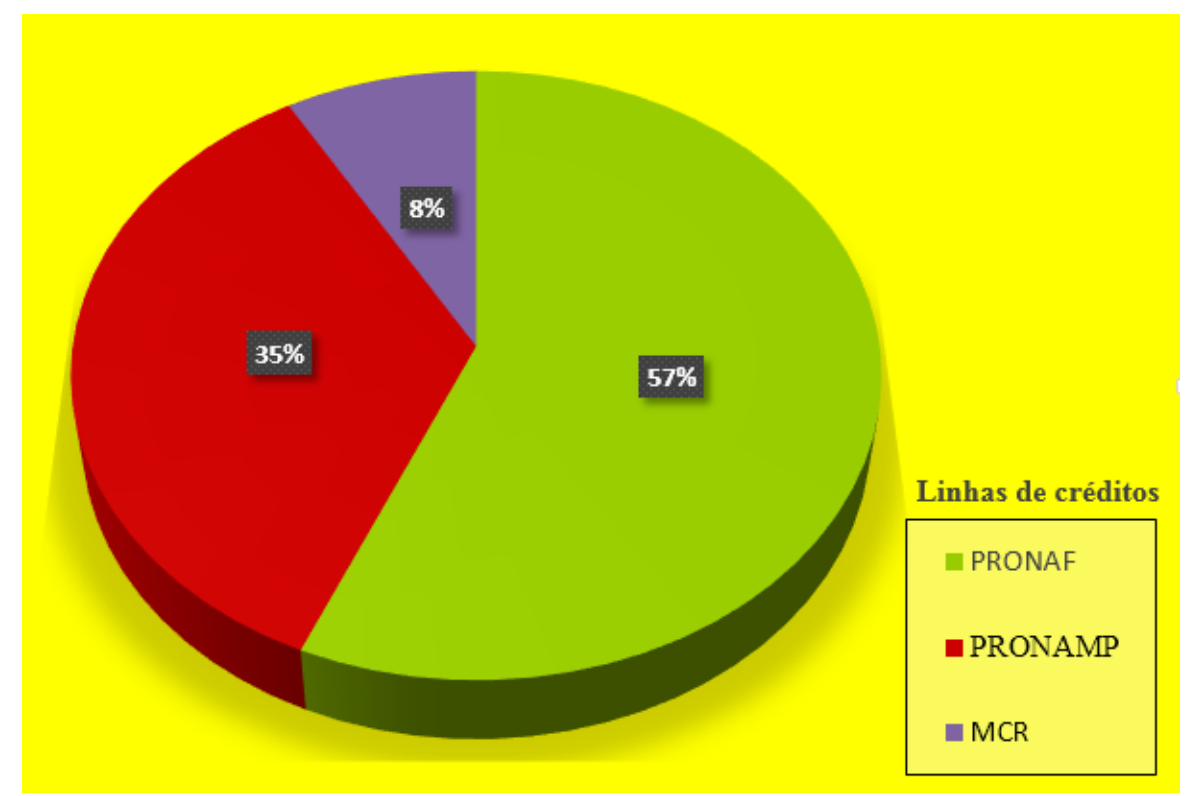

Figura 04: Créditos do Banco do Brasil - 2015.

Fonte: Banco do Brasil - Agência Frei Paulo/SE, outubro de 2015.

Os recursos financeiros atrelados aos negócios da agricultura provenientes do sistema de crédito bancário ou da renda dos comerciantes proprietários de terras que investem no setor agrícola estão transformando as relações econômicas, sociais, políticas e ambientais dos municípios produtores de milho. Nota-se, portanto, que a presença dos recursos disponibilizados ao financiamento agrícola, tem promovido a modernização da produção e ampliado os laços de 
dependência dos produtores com as instituições financeiras (Banco do Brasil - BB; Banco do Nordeste - BNE e Banco do Estado de Sergipe - BANESE) .

Do ponto de vista da influência do Pronaf entre os produtores detentores de terras ocupadas na área da sub-bacia nota-se que o programa tem promovido mudanças na estrutura produtiva do agronegócio, embora, perceba-se a manutenção da estrutura agrária e a permanência do modo de produção voltado à monocultura do milho. Desse modo, em termos de números de contratos e montantes liberados, constata-se a relevância do Pronaf, pois suas diversas modalidades vêm possibilitando a inserção de vários grupos de produtores no processo produtivo. Vale salientar que, ainda persistem no campo os conflitos relacionados ao acesso à terra e, ao considerar a realidade de vários pequenos proprietários, sobressai entre estes as dificuldades socioeconômicas de viver no campo e a tendência ao êxodo rural.

Portanto, conclui-se que as políticas do Estado possibilitam a reafirmação dos interesses do agronegócio, garantindo as demandas financeiras responsáveis pela consolidação da atividade monocultora do milho. Esta estrutura econômica financiada pelo Estado tem contribuído na rentabilidade vivenciada entre os produtores de milho, mas de forma negativa mascara a permanência da concentração fundiária, os conflitos, a exclusão tecnológica, a exploração dos trabalhadores e a degradação do meio ambiente.

\subsection{Os Impactos Ambientais Decorrentes dos Cultivos de Milho}

O milho tem contribuído para a abertura de novas áreas, como enfatiza a pesquisa de Santos (2012, p. 44) realizada no município de Carira. A autora mostra a ocorrência das queimadas e comenta que "áreas antes usadas para criação de gado são substituídas pela monocultura do milho. A busca pela ampliação das áreas de cultivo tem levado ao desmatamento de áreas de Caatinga para uso da agricultura”. Assim, a retirada da vegetação para fins agrícolas faz parte do contexto do milho na sub-bacia, representando, à posterior, um fator de desequilíbrios e de degradação ambiental. Outra situação que implica no desmatamento para o cultivo de milho é a retirada da formação vegetal nativa de áreas marginais aos rios. Esta situação de degradação das planícies fluviais tende a provocar intensos impactos ambientais em áreas que teoricamente deveriam estar cobertas pelas matas ciliares.

Quanto à preservação da biodiversidade nas propriedades produtoras de milho da sub-bacia, verificou-se a existência de manchas de matas nativas em todos os imóveis, muito embora não apresentassem registros de reserva legal. Na opinião dos produtores, a única prática de preservação das áreas está em não desmatar para evitar problemas com a fiscalização do Instituto Brasileiro do Meio Ambiente e dos Recursos Naturais Renováveis (IBAMA). Essa situação chama a atenção para 
algumas pontualidades: de acordo com 2 produtores que adquirem financiamento, as matas são mantidas para facilitar o crédito agrícola, sem que haja fiscalização quanto à exigência de $20 \%$ da propriedade coberta com matas, teoricamente os produtores/arrendatários informam ao banco que a propriedade possui o pré-requisito ao financiamento, mas na prática não existe o tamanho da área informada na documentação.

Dessa forma, pode-se perceber que a dinâmica produtiva proporcionada pelo agronegócio do milho pautada no uso de produtos químicos e na adoção de modernas práticas de manejo das lavouras tende a provocar diversos impactos ambientais tais como o desmatamento, a erosão e a salinização dos solos. O aumento dos riscos de contaminação dos mananciais de água com agrotóxicos influencia no assoreamento dos cursos fluviais e compromete a saúde humana e a biodiversidade devido à quebra da cadeia alimentar, podendo causar a extinção de espécies da fauna e da flora das áreas da sub-bacia.

\section{CONSIDERAÇÕES FINAIS}

Os indicadores de modernização apresentados na pesquisa mostram a tendência de expansão das áreas de cultivos agrícolas na sub-bacia. Esta ampliação das plantações respalda-se no fortalecimento das vendas de produtos agrícolas, na aquisição de novas máquinas e implementos, na provável elevação do número de financiamentos bancários, na produtividade das lavouras e na garantia de mercado para a comercialização do milho. Tendo em vista este fortalecimento do agronegócio, pressupõe-se de forma análoga a intensificação dos impactos ambientais e a consequente fragilização do sistema ambiental da sub-bacia.

De modo geral, os interesses do campo estão focados na produtividade, na rentabilidade e na garantia da produção e preços do milho. A potencialidade agrícola dos solos, a eficiência das sementes geneticamente modificadas, a pujança da mecanização agrícola, o uso de produtos químicos e a facilidade do acesso ao crédito bancário representam os fatores preponderantes que justificam o domínio da produção de milho na sub-bacia. Todavia para os envolvidos no agronegócio, os atributos ambientais são insignificantes e estes incorporam a ideia de que as práticas agrícolas pouco modificam a paisagem. Esses argumentos direcionados apenas para a produção enaltecem os investimentos direcionados ao agronegócio, tornando irrelevantes as consequências da intensa exploração dos recursos naturais.

Acerca de uma década, o milho desaponta como a produção agrícola que gera mais lucros e transforma rapidamente áreas que antes eram exploradas pela pecuária. Atualmente os elevados investimentos proporcionados pelo agronegócio do milho comprovam o aumento das áreas plantadas e a maior rentabilidade adquirida com a comercialização dos grãos. A introdução de 
sementes selecionadas, de corretivos químicos nos solos, e com o uso dos agrotóxicos, atrelados à mecanização agrícola e a intensiva exploração da área agricultável da sub-bacia, está promovendo brusca modificações no processo produtivo no campo, consolidando o domínio da monocultura do milho.

Assim, a presença da biotecnologia e das modernas máquinas agrícolas reflete a imagem do setor agropecuário como altamente inovador no âmbito econômico, mas permanece resistente no aspecto socioambiental. Esta contradição reitera, por um lado, à concentração da terra e a manutenção das desigualdades sociais no campo, e por outro, reafirma o caráter economicista da produção agrícola que implica em estabelecer estratégias voltadas ao aumento da produção e da rentabilidade das lavouras. Os produtores agrícolas e as empresas envolvidas no agronegócio buscam a produtividade e a riqueza, porém pouco se preocupam com a qualidade de vida dos trabalhadores e não designam investimentos para a manutenção da biodiversidade. Como visto, na sub-bacia, visualiza-se a continuidade na exploração agrícola, mas não se vislumbra investimentos que possam minimizar os riscos ambientais. A coerente transferência de recursos financeiros para cuidar da biodiversidade ou direcionar investimentos para a estruturação de uma eficiente rede de fiscalização nas áreas agrícolas representariam propostas condizentes com a perspectiva de sustentabilidade socioambiental das áreas de cultivos de milho.

\section{REFERÊNCIAS}

CARVALHO, M. E. S. A questão hídrica na bacia sergipana do Vaza-Barris. Tese de Doutorado apresentado ao Programa de Pós Graduação em Geografia PPGEO/UFS. São Cristóvão, 2010.

CPRM/CODISE. Serviço Geológico do Brasil. Levantamento Geológico do Estado de Sergipe, 2002.

IBGE, Instituto Brasileiro de Geografia e Estatística 2013.

SANTOS, C. Níveis tecnológicos dos agroecossistemas do milho no Estado de Sergipe. Dissertação de Mestrado apresentado ao Programa de Pós Graduação em Geografia PPGEO/UFS, São Cristóvão, 2012.

Recebido em: 14/08/2016

Aceito para publicação em: 01/10/2016 